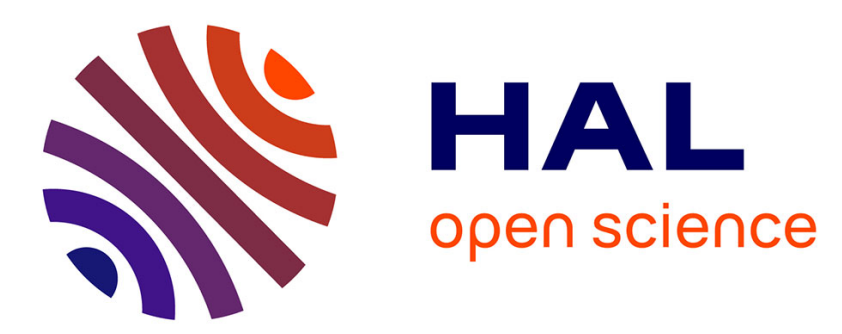

\title{
Pressure variation of the critical temperature in nitroethane-isooctane and nitroethane-3-methylpentane mixtures
}

D. Beysens, R. Tufeu

\section{- To cite this version:}

D. Beysens, R. Tufeu. Pressure variation of the critical temperature in nitroethane-isooctane and nitroethane-3-methylpentane mixtures. Revue de Physique Appliquée, 1979, 14 (11), pp.907-909. 10.1051/rphysap:019790014011090700 . jpa-00244678

\section{HAL Id: jpa-00244678 \\ https://hal.science/jpa-00244678}

Submitted on 1 Jan 1979

HAL is a multi-disciplinary open access archive for the deposit and dissemination of scientific research documents, whether they are published or not. The documents may come from teaching and research institutions in France or abroad, or from public or private research centers.
L'archive ouverte pluridisciplinaire $\mathbf{H A L}$, est destinée au dépôt et à la diffusion de documents scientifiques de niveau recherche, publiés ou non, émanant des établissements d'enseignement et de recherche français ou étrangers, des laboratoires publics ou privés. 


\title{
REVUE DE PHYSIQUE APPLIQUÉE
}

Classification

Physics Abstracts

$64.70 \mathrm{~J}$

\section{Pressure variation of the critical temperature in nitroethane-isooctane and nitroethane-3-methylpentane mixtures}

\author{
D. Beysens and R. Tufeu (*) \\ Service de Physique du solide et résonance magnétique, \\ DPh-G/PSRM, CEN Saclay, BP 2, 91190 Gif sur Yvatte, France
}

(Reçu le 5 juillet 1979, révisé le 30 août 1979, accepté le 11 septembre 1979)

Résumé. - La variation de la température critique $T_{\mathrm{c}}$ avec la pression $p$ a été déterminée dans les mélanges de nitroéthane-isooctane et nitroéthane-3-méthylpentane. Pour ce dernier système, la valeur $\mathrm{de}\left(\mathrm{d} T_{\mathrm{c}} / \mathrm{d} p\right)$ permet de comparer l'amplitude de la partie divergente de la chaleur spécifique $C_{\mathrm{p}, x_{\mathrm{c}}}$ avec les prédictions du groupe de renormalisation.

Abstract. - The variation of the critical temperature as a function of pressure in nitroethane-isooctane (N-I) and nitroethane-3-methylpentane (N-3M) mixtures has been experimentally determined. Since both mixtures exhibit components having nearly the same refractive index, special care had to be taken to see the transition. The following values were found :

and

$$
\left(\frac{\mathrm{d} T_{\mathrm{c}}}{\mathrm{d} p}\right)_{\mathrm{N}-1}=(2.6 \pm 0.5) \times 10^{-8} \mathrm{~K} \cdot \mathrm{Pa}^{-1}
$$

$$
\left(\frac{\mathrm{d} T_{\mathrm{c}}}{\mathrm{d} p}\right)_{\mathrm{N}-3 \mathrm{M}}=(3.7 \pm 0.5) \times 10^{-8} \mathrm{~K} \cdot \mathrm{Pa}^{-1} .
$$

For N-3M, a comparison is made of the amplitude of the diverging part of the specific heat with the renormalization group prediction.

In the field of critical phenomena, the specific heat anomaly in fluids (at constant volume $C_{\mathrm{v}}$ in pure fluids, at constant pressure and concentration $C_{\mathrm{p}, \mathrm{x}}$ in binary mixtures) remains a point which has not been much investigated [1]. This quantity exhibits a power law divergence governed by the exponent $\alpha(=0.110)$ [2].

In binary fluid mixtures, $C_{\mathrm{p}, \mathrm{x}}$ is related to the thermal expansion coefficient $\alpha_{p, x}=-\rho^{-1}(\partial \rho / \partial T)_{p, x}$ through the relationship :

$$
C_{\mathrm{p}, \mathrm{x}}=C_{V, \mathbf{x}}+T \cdot V \cdot \alpha_{\mathrm{p}, \mathrm{x}} \cdot(\partial p / \partial T)_{V, \mathbf{x}} .
$$

Volume $V$ or density $\rho$ measurements can be very accurate. From direct measurements of the density, a relative precision of $2 \times 10^{-6}$ can be achieved. Using an interferometric method, since the variation of the index of refraction $n$ is proportional to the

(*) L.I.M.H.P. CNRS, Centre Universitaire Paris-Nord, avenue J.-B.-Clément, 93430 Villetaneuse. variation of the density, a precision of $4 \times 10^{-7}$ can be obtained [3].

Therefore the determination of the quantity $\mathrm{d} T_{\mathrm{c}} / \mathrm{d} p$ (which is equivalent to $(\partial p / \partial T)_{V, x_{c}}^{-1}$ at the critical point), where $T_{\mathrm{c}}$ is the critical temperature and $x_{\mathrm{c}}$ the critical concentration, is of first importance when testing the theoretical prediction of the critical amplitude of $C_{\mathrm{p}, \mathrm{x}}$ [4-6] through the density measurements. Of course, the stronger the magnitude of $\left(\mathrm{d} T_{\mathrm{c}} / \mathrm{d} p\right)$, the more precise will be the test. The knowledge of this contribution is moreover needed if other phenomena, such as local field effects in the refractive index [7, 8], are to be evidenced.

So we have experimentally determined the variation of $T_{\mathrm{c}}$ with pressure, which was varied from atmospheric pressure up to $125 \times 10^{5} \mathrm{~Pa}$ in the systems (N-I) nitroethane-isooctane and (N-3M) nitroethane3-methylpentane. These mixtures are of special interest : concerning (N-I) the matching for each component of $n, \alpha_{\mathrm{p}, \mathrm{x}}$ and $(\partial n / \partial T)_{p}$ allows interesting simplifications to be made when evaluating the regular 
contributions, and concerning $(\mathrm{N}-3 \mathrm{M})$, a careful study of the density variation near $T_{\mathrm{c}}$ has been previously performed [9], where only the $\left(\mathrm{d} T_{\mathrm{c}} / \mathrm{d} p\right)$ value was missing to enable comparison of the amplitudes with the theoretical predictions.

These two mixture exhibit a close matching in the refractive index of the components, thus a special experiment had to be set-up in order to determine the transition temperature.

1. Determination of $\left(\mathrm{d} T_{\mathrm{c}} / \mathrm{d} P\right)$. - The liquids which composed the mixture were of the quality Reference substance for gas chromatography for isooctane and 3-methylpentane. Nitroethane was obtained from a careful distillation of a $96 \%$ pure commercial material. Chromatography and N-M-R measurements showed that after distillation the impurity level was less than $0.5 \%$.

The critical nitroethane mass fraction of (N-I) is 0.4650 [10] and that of $(\mathrm{N}-3 \mathrm{M})$ is 0.4646 [11]. Each sample was prepared in a glass tube able to support pressures up to $200 \times 10^{5} \mathrm{~Pa}$. The experimental concentrations were $(\mathrm{N}-\mathrm{I}) 0.469 \pm 0.015$ and $(\mathrm{N}-3 \mathrm{M}) 0.468 \pm 0.015$, the uncertainties being due to the small quantity of liquid used. This tube was then frozen and joined to a branch of a stainless steel Utube, the other extremity of which being connected to a mercury reservoir. Vacuum was made and mercury reached the frozen mixture. The glass and U-tube were submerged in a water bath with thermal regulation $\pm 0.01 \mathrm{~K}$. Mercury was put under pressure with gaseous Argon. The pressure was measured with a calibrated Bourdon gauge and was varied up to $125 \times 10^{5} \mathrm{~Pa}$.

The main problem with these liquids was to see the meniscus when transition took place : the refractive index difference of components in (N-I) is $1 \times 10^{-3}$ [8], and $1.5 \times 10^{-2}$ [12] in (N-3M) at $\lambda=6328 \AA$. So we had to set-up a special experiment :

A pin-point, very intense, white light source was used to cast on the back of the bath the shadow due to the refractive index gradient $\Delta n / \Delta Z, \Delta Z$ corresponding to the meniscus width. This method is very sensitive, and a rough estimation based on the width of the meniscus (i.e. the correlation length $\xi$ [13]), would enable refractive index differences of $5 \times 10^{-5}$, at $T-T_{\mathrm{c}} \simeq 10^{-2}{ }^{\circ} \mathrm{C}$, to be observed.

The procedure was the following for each measurement : the mixture was mixed by heating the glass tube and varying the pressure; then the thermostat was set at a temperature high enough so that the mixture remained in the one phase region when the desired pressure was applied. When the thermal equilibrium was reached, the temperature was lowered. Another equilibrium takes place and an observation was done in order to detect the meniscus. If it is not visible, another step was performed. The reproductibility was checked.

Among all causes of uncertainties, the main pro- blem was the matching of refractive indices for (N-I), this phenomenon leading to an error of $\pm 0.05 \mathrm{~K}$ on the critical temperature. For $(\mathrm{N}-3 \mathrm{M})$ the error was mainly due to the thermal regulation $( \pm 0.01 \mathrm{~K})$.

The results are shown in figures 1 and 2 . The values, fitted to a linear variation with the statistical refining program due to $M$. Tournarie [14], are :

Nitroethane-Isooctane

$$
\left(\mathrm{d} T_{\mathrm{c}} / \mathrm{dP}\right)=(2.6 \pm 0.5) 10^{-8} \mathrm{~K} \cdot \mathrm{Pa}^{-1}
$$

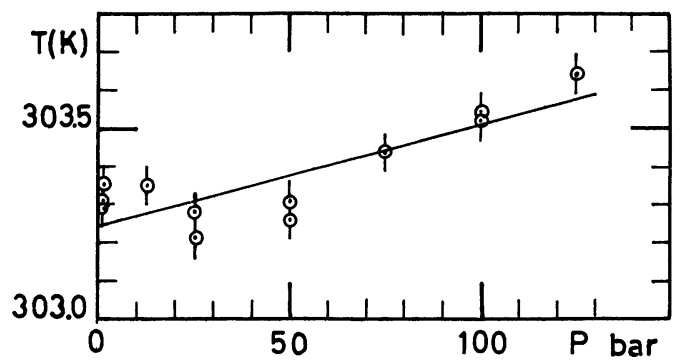

Fig. 1. - Pressure variation of the transition temperature $T_{\mathrm{c}}$ in the critical mixture of Nitroethane-Isooctane.

Nitroethane-3-methylpentane

$$
\left(\mathrm{d} T_{\mathrm{c}} / \mathrm{d} P\right)=(3.7 \pm 0.5) 10^{-8} \mathrm{~K} \cdot \mathrm{Pa}^{-1}
$$

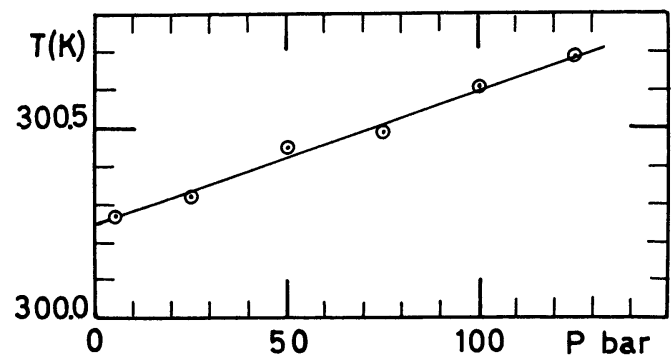

Fig. 2. - Pressure variation of the transition temperature $T_{\mathrm{c}}$ in the critical mixture of Nitroethane-3-Methylpentane.

We think that the slight curvature visible in the N-I system is meaningful. Indeed at pressure $\simeq 50$ bar the matching in refractive index of components is the closest (due to small differences in the $(\partial n / \partial p)_{T}$ coefficients) so that the meniscus can be detected only for temperatures slightly lower than $T_{\mathrm{c}}$.

2. Discussion. - These values are very small compared to most of the critical binary mixtures [15] where $\left(\mathrm{d} T_{\mathrm{c}} / \mathrm{d} P\right) \simeq 2 \times 10^{-7} \mathrm{~K} \cdot \mathrm{Pa}^{-1}$, they are consistent with the small values of the mixing volume excess. We experimentally verified that the volume change in (N-I) was less than $1 \%$, and density measurements of ref. [9] show that the excess volume in system $(\mathrm{N}$ $3 \mathrm{M}$ ) was lower than $0.1 \%$. The critical contribution to the thermal expansion coefficient for system $\mathrm{N}$ - 
3M was estimated [9] as (with $\alpha=0.11$ instead of $0.14)$ :

$$
\alpha_{\mathrm{P}, x_{\mathrm{c}}}^{0}=(4.9 \pm 1) 10^{-5} \mathrm{~K}^{-1}
$$

so that the amplitude $C_{\mathrm{P}, x_{\mathrm{c}}}^{0}$ of the diverging part of $C_{\mathrm{P}, x_{\mathrm{c}}}$ can be estimated using (1) and compared to the predictions of the renormalization group theory by means of the two-scale factor hypothesis : the dimensionless quantity $X=\left(R_{\xi}^{+}\right)^{3}$ is expected to be an universal constant $\sim 1.6 \times 10^{-2}$ and is related to the exponent $\alpha=0.11$, the critical density $\rho_{\mathrm{c}}$, the correlation length $\xi_{0}$, and the Boltzmann constant $k_{\mathrm{B}}$ through the relationship

$$
X=k_{\mathrm{B}}^{-1} \alpha \rho_{\mathrm{c}} C_{P, \mathbf{x}_{\mathrm{c}}}^{0} \xi_{0}^{3} .
$$

Since

$$
\rho_{\mathrm{c}} C_{P, \mathrm{x}_{\mathrm{c}}}^{0}=T_{\mathrm{c}}\left(\mathrm{d} T_{\mathrm{c}} / \mathrm{d} P\right)^{-1} \alpha_{P, \mathrm{x}_{\mathrm{c}}}^{0},
$$

and $\xi_{0}=(2.26 \pm 0.04) 10^{-10} \mathrm{~m}$ [15], we deduce
$X=(3.7 \pm 1.5) \times 10^{-2}$, i.e. a value of the same order of magnitude as expected. Considering the weakness of the divergence and the fact that gravity effects may have affected the measurements, the agreement is reasonable.

3. Conclusion. - Precise measurements of the quantity $\left(\mathrm{d} T_{\mathrm{c}} / \mathrm{d} P\right)$ are of considerable interest in a critical binary fluid when testing with the density behaviour the amplitude relations of the weakly diverging part of $C_{\mathrm{p}, \mathrm{x}_{\mathrm{c}}}$. In the mixture studied here, the values found are very small compared to those commonly observed. Moreover the difficulty of the experimental determination was increased by the matching in refractive indices, needing a special experiment to be set-up. The order of magnitude of the diverging part of the thermal expansion coefficient in the system nitroethane-3-methylpentane nevertheless compares favourably with the renormalization group prediction.

\section{References}

[1] StANLEY, H. E., Introduction to phase transitions and critical phenomena (Clarendon, Oxford) 1971.

[2] Le Guillou, J. C. and Zinn-Justin, J., Phys. Rev. Lett. 39 (1977) 95.

[3] Beysens, D., Rev. Sci. Instrum. 15 (1979) 509.

[4] Staufer, D., Ferer, M. and Wortis, M., Phys. Rev. Lett. 29 (1972) 345.

[5] Klein, H. and Woermann, J. Chem. Phys. 64 (1976) 5316; 65 (1976) 1593 and ref. herein.

[6] Hohenberg, P. C., Aharony, A., Halperin, B. I. and SigGiA, E. D., Phys. Rev. B 13 (1976) 2986.

[7] Hartley, C. L., Jacobs, D. T., MOCKLER, R. C. and O'Sullivan, W. J., Phys. Rev. Lett. 33 (1974) 1129.

[8] Beysens, D. and Wesfrem, J., J. Chem. Phys. 71 (1979) 119.

[9] Greer, S. C., and Hocken, R., J. Chem. Phys. 63 (1975) 5067.
.[10] Beysens, D., J. Chem. Phys. 71 (1979) 2557.

[11] Wims, A. M., Mc Intyre, D. and Hynne, F., J. Chem. Phys. 50 (1969) 616.

[12] Beysens, D. and Calmettes, P., J. Chem. Phys. 66 (1977) 766.

[13] Fisk, S. and Widom, B., J. Chem. Phys. 50 (1969) 3219.

[14] Tournarie, M., J. Physique, 30 (1969) 47.

[15] See for instance :

Timmermans, J., Physico-chemical constants of binary systems in concentrated solutions Vol. 1 (Intersc. Pub. Inc. N.Y.) 1959.

[16] See for instance :

Chang, R. F., Burstyn, H., Sengers, J. A. and Bray, A. J., Phys. Rev. Lett. 37 (1976) 1481 and

Calmetres, P., Thesis (unpublished), Paris (1978). 